\title{
Effects of Prenatal Dexamethasone on Development of Ornithine Decarboxylase Activity in Brain and Peripheral Tissues of Rats
}

\author{
HERNAN A. NAVARRO, JEAN LACHOWICZ, JORGE BARTOLOME, WILLIAM L. WHITMORE, \\ AND THEODORE A. SLOTKIN \\ Department of Pharmacology, Duke University Medical Center, Durham, North Carolina 27710
}

\begin{abstract}
The use of glucocorticoids in the management of neonatal respiratory distress syndrome may be associated with abnormalities of growth and neurologic development. In our study, pregnant rats received either 2 or $0.2 \mathrm{mg} / \mathrm{kg}$ of dexamethasone on gestational days 17,18 , and 19 and tissues of the offspring were examined for ornithine decarboxylase activity, a marker enzyme for perturbations of cellular maturation. Acutely, the higher dose of dexamethasone suppressed ornithine decarboxylase activity in all tissues except lung, where a short-term stimulation was obtained. Repeated administration of $2 \mathrm{mg} / \mathrm{kg}$ resulted in an ornithine decarboxylase pattern consistent with delayed cellular development in all tissues (suppressed activity followed by prolonged postnatal elevations), accompanied by impaired viability and general growth. Lowering the dose of dexamethasone to $0.2 \mathrm{mg} / \mathrm{kg}$ eliminated all the adverse effects on viability but still produced perturbations of tissue ornithine decarboxylase, most notably a prolonged suppression of activity across all brain regions. These data suggest that administration of glucocorticoids even at the threshold for effects on respiratory function, may compromise neural development. (Pediatr Res 24: 465-469, 1988)
\end{abstract}

\section{Abbreviations}

ANOVA, analysis of variance

DEX, dexamethasone

ODC, ornithine decarboxylase

$\mathrm{WB}$, whole brain

Respiratory distress syndrome is a leading cause of neonatal death in preterm infants. Early administration of glucocorticoids is the treatment of choice due to the promotional effect of these agents on maturation of lung surfactant production and release $(1,2)$. However, the high doses of these agents typically used in a therapeutic setting (3) may have adverse effects on development of other structures. In particular, the CNS is thought to be a target of steroid actions on cellular replication and differentiation which may ultimately compromise behavioral development (4-7).

In our study, we have examined the effects of DEX on maturation of brain regions and the lung. The doses chosen $(0.2$ to 2 $\mathrm{mg} / \mathrm{kg}$ ) span the range from subeffective stimulation of surfactant production to therapeutic doses (3). To monitor the impact on

Received March 18, 1988; accepted June 2, 1988

Correspondence Dr. T. Slotkin, Box 3813, Duke University Medical Center, Durham, NC 27710.

Supported by USPHS Grant HD-09713 and EPA CR-813769. cellular maturation, we have measured ODC activity: ODC catalyzes the initial step in the formation of the polyamines, molecules that regulate DNA, RNA, and protein synthesis during cell replication and differentiation $(8,9)$. ODC has been shown to be a sensitive marker enzyme for perturbations of development elicited by hormones, drugs, or adverse environmental conditions, especially in immature brain $(6,7,9-12)$. Three brain regions were chosen: the midbrain plus brainstem, where neuronal replication occurs earliest, the cerebellum, where the majority of neurons replicates after birth, and the cerebral cortex, with an intermediate timetable of development $(13,14)$. In this way, selective actions of DEX on replicative or postreplicative events in the CNS have been examined and contrasted with effects on ODC in peripheral tissues (lung, heart, kidney).

\section{MATERIALS AND METHODS}

Timed-pregnant Sprague-Dawley rats (Zivic-Miller Laboratories, Allison Park, PA) were shipped on the 4th day of gestation (before implantation of the embryo in the uterine wall) by climate-controlled truck (total transit time, $12 \mathrm{~h}$ ). After arrival, the animals were housed individually in breeding cages and allowed food and water ad libitum. To examine the acute effects of a single injection of DEX, dams were administered DEX phosphate (Merck, Sharp \& Dohme, Rahway, NJ) at a dose of 0.2 or $2.0 \mathrm{mg} / \mathrm{kg}$ subcutaneously (dissolved in deionized water, injection volume $1 \mu \mathrm{l} / \mathrm{g}$ body weight) either 24,12 , or $4 \mathrm{~h}$ before killing on gestational day 19; controls received equivalent volumes of vehicle. For longitudinal studies of long-term effects of DEX, dams were injected on the 17th, 18th, and 19th days of gestation. On the 19th and 21 st day of gestation, dams were killed by decapitation and the fetuses rapidly excised and dissected for tissue analysis of either whole brain or brain regions and peripheral organs; a maximum of 5 min elapsed until the chilling of the fetal tissues, and in no case did the order in which the fetuses were dissected have any discernible influence on ODC activity. Determinations on gestational day 19 were done $24 \mathrm{~h}$ after the previous day's injection. Maternal weight gain and mortality were recorded and at parturition, proportions of dams delivering pups and litter size were noted.

For studies with the low dose of dexamethasone, pups were randomized at birth within their respective treatment groups and then redistributed to the nursing dams with a split cross-foster design: half the control pups were nursed by control dams and half by DEX-treated dams; pups exposed to DEX were divided similarly. This design enables the detection of differences in development caused by anomalous maternal caretaking caused either by the prenatal drug treatment or by failure of normal dams to care properly for treated pups. Because a significant proportion of the dams receiving the high dose of DEX failed to give birth, animals in this study were all reared by cross-fostering 
to control dams. In all cases, litter sizes were maintained at 912 pups to insure standard nutritive status; randomization was carried out before each experiment and pups of both sexes were chosen from several different cages at each age point. Animals were weighed, decapitated, and brains dissected into three regions: blunt cuts were made through the cerebellar peduncles, whereupon the cerebellum (including flocculi) was lifted from the underlying tissue; a cut was made rostral to the thalamus to separate the cerebral cortex from the midbrain plus brainstem; the heart, lungs, and kidneys were also removed. Biochemical assays were performed on fresh tissue. In cases where there was insufficient tissue from one pup or fetus to perform the assays, brain regions and organs from two to four animals were combined for a single determination.

Tissues were weighed and homogenized in 19-29 vol of 10 $\mathrm{mM}$ Tris ( $\mathrm{pH}$ 7.2) and ODC assays conducted in duplicate in the $26,000 \times g$ supernatant solution as described by Lau and Slotkin (15); the incubation medium contained final concentrations of $50 \mu \mathrm{M}$ pyridoxal-5' -phosphate (Sigma Chemical Co., St. Louis, MO), $1.5 \mathrm{mM}$ dithiothreitol (Bachem Inc., Torrance, CA), and $4.5 \mu \mathrm{M} \mathrm{L}-\left[1-{ }^{14} \mathrm{C}\right]$ ornithine (New England Nuclear, Boston, MA; sp. act. $53.4 \mathrm{mCi} / \mathrm{mmol}$ ). Measurements of brain ODC were discontinued after 16 days postnatally because of the extremely low values characteristic of mature neural tissue (9).

Statistics. Data are presented as means \pm SE. For the prenatal data, fetuses of each dam were considered to represent a single determination; thus, where seven to eight prenatal determinations are indicated, the results represent seven to eight dams (for each of which multiple fetuses were examined). In view of the randomization procedure used after birth, the indicated number of determinations represents individual animals except where insufficient tissue was available, as described above. The proportion of dams giving birth (a nonparametric variable) was assessed by Fisher's exact test. For parametric variables in longitudinal studies and/or studies in the three brain regions or peripheral organs, comparisons were assessed by ANOVA (with log transform because of heterogeneity of variance), with separation of factors by age, region, treatment, and dam. Lower-order ANOVA was then run where treatment was interactive with other variables. For acute studies, Duncan's multiple range test was applied to detect individual differences from control values. For all tests, differences were considered significant at the level of $p<0.05$.

To simplify data presentation of the postnatal age points in the split cross-fostering design, results were pooled according to the treatment of the pups (i.e. values from control pups reared by control dams were combined with values from control pups reared by DEX-treated dams; values from DEX-treated pups reared by controls were combined with DEX-treated pups reared by treated dams). These modifications are justified because: 1 ) cross-fostering of control pups to DEX dams had only minor effects on tissue weights (less than 2-3\%) and had no significant effect on ODC activity; 2) DEX-treated pups reared by control dams had tissue weights indistinguishable from those reared by DEX-treated dams; 3) although DEX-treated pups reared by DEX-treated dams had higher ODC activities than those reared by control dams, the treatment-induced differences were significant regardless of if the data were pooled or separated by treatment of the dam (data not shown).

\section{RESULTS}

Effects on viability and growth. Dams given either the high or low dose of DEX showed a retardation in weight gained over the last few days of pregnancy (Table 1). In the animals given $2 \mathrm{mg} /$ $\mathrm{kg}$, approximately one-third of the dams resorbed their fetuses and failed to give birth, as compared to only $10 \%$ in the control and low-dose DEX groups. Litter size was also reduced by exposure to the high dose of DEX.
Offspring in the high-dose group were severely underweight for at least $2 \mathrm{wk}$, but recovered to normal shortly after weaning (Fig. 1). Animals exposed to $0.2 \mathrm{mg} / \mathrm{kg}$ of DEX remained within normal limits through gestational day 19 and were only slightly subnormal during the first postnatal week. DEX also had an adverse effect on brain region weights in the offspring (Fig. 2, top). In animals exposed to $2 \mathrm{mg} / \mathrm{kg}$ of DEX, deficits in brain region weights were $10-20 \%$ at birth and resolved to normal values by the end of the experiment; in all cases, the effects of high-dose DEX on brain region weight were less severe than those on body weight. At the lower dose, significant reductions in brain region weight were of even smaller magnitude.

Global statistical analysis of peripheral organ weights also revealed significant growth impairment caused by DEX (Fig. 2, bottom). With the high dose, deficits in lung, heart, and kidney weight were comparable in magnitude and time course to those seen in body weight. At the lower dose, smaller reductions were obtained and differences were significant for lung and kidney but not heart.

Table 1. Maternal wt and offspring viability*

\begin{tabular}{ccc}
\hline & \multicolumn{2}{c}{ Days of gestation } \\
\cline { 2 - 3 } Treatment & 17 & \multicolumn{1}{c}{21} \\
\hline Maternal wt $(\mathrm{g})$ & $350 \pm 7$ & $398 \pm 8$ \\
Control & $337 \pm 9$ & $352 \pm 8 \dagger$ \\
DEX $2 \mathrm{mg} / \mathrm{kg}$ & & \\
& $360 \pm 5$ & $416 \pm 8$ \\
Control & $369 \pm 5$ & $374 \pm 9 \dagger$ \\
DEX $0.2 \mathrm{mg} / \mathrm{kg}$ &
\end{tabular}

Offspring viability

\begin{tabular}{lcc} 
& $\begin{array}{c}\text { Dams giving } \\
\text { birth (\%) }\end{array}$ & Litter size \\
\cline { 2 - 3 } Control & 89 & $12.1 \pm 0.4$ \\
DEX $2 \mathrm{mg} / \mathrm{kg}$ & $69 \dagger$ & $8.2 \pm 0.7 \dagger$ \\
DEX $0.2 \mathrm{mg} / \mathrm{kg}$ & 89 & $12.2 \pm 0.6$
\end{tabular}

* Data represent means and SE of values obtained from 47 control dams, 13 dams in the high-dose DEX group and 37 dams in the lowdose DEX group. Two-way ANOVA indicates a significant reduction in maternal weight caused by DEX.

$\dagger$ Individual points at which the DEX groups differ from the control in maternal weight and litter size (Duncan's multiple range test) and in the proportion of dams giving birth (Fisher's exact test).

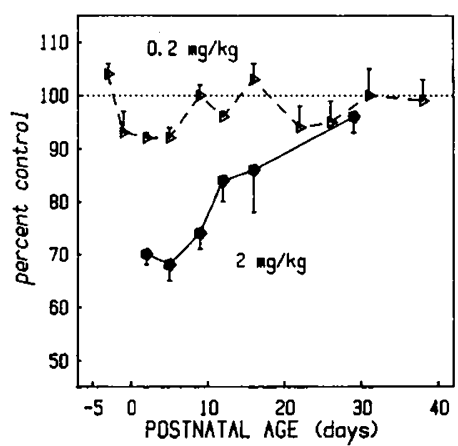

Fig. 1. Effects of maternal DEX treatment on body weights in the offspring. Data represent means and SE of values from 6-35 animals in each group at each age (number of dams for prenatal points, individual pups for postnatal points). ANOVA indicates significant reductions in body weight (main treatment effect and interaction of treatment $\times$ age at either dose). 
Control values for body, brain region, and organ growth rates (data not shown) were consistent with previous reports $(14,16-$ 18).

Effects of $2 \mathrm{mg} / \mathrm{kg} \mathrm{DEX}$ on $O D C$. Acute administration of the high dose of DEX $(2 \mathrm{mg} / \mathrm{kg})$ caused a net reduction in ODC activity in fetal WB, reaching $60 \%$ of control levels $12 \mathrm{~h}$ after drug administration and recovering by $24 \mathrm{~h}$ (Fig. 3). Similar suppressant effects were seen in heart, liver, and kidney. Notably, in the lung, a marked stimulation occurred at $4 \mathrm{~h}$ before it, too, lost activity.

The period after birth is marked by a rapid decline of brain ODC from its high initial levels to the low activity characteristic of the adult (9). Animals exposed to the high dose of DEX displayed initial suppression of ODC activity in fetal WB and postnatally across all three brain regions, followed by a prolonged period of elevated activity (Fig. 4), a pattern usually associated with delayed neuronal development or neurotoxic insult $(6,7,9$, $10,12)$. In the peripheral tissues, prenatal exposure to the high dose of DEX also caused net elevations of ODC activity in peripheral tissues but did not interfere with the postweaning spike of activity characteristic of the lung and kidney $(19,20)$.

Effects of $0.2 \mathrm{mg} / \mathrm{kg} \mathrm{DEX}$ on $O D C$. Lowering the maternal dose of DEX to $0.2 \mathrm{mg} / \mathrm{kg}$ did not alter the general pattern of acute effects of the drug on fetal ODC activity, but did reduce the magnitude of the suppression (Fig. 5). Significant lowering of enzyme activity was still clearly detectable in heart, liver, and kidney. The short-term stimulation of activity in lung was present at this lower dose, but attenuated relative to the effect seen at the higher dose; however, the later suppression of lung ODC persisted longer at $0.2 \mathrm{mg} / \mathrm{kg}$.

Repeated administration of $0.2 \mathrm{mg} / \mathrm{kg}$ of DEX to pregnant rats resulted in suppression of ODC activity in fetal WB and brain regions, an effect that persisted into the postnatal period (Fig. 6). Unlike the higher dose of DEX, there was no subsequent rebound elevation of enzyme activity in the brain regions. Differences were also seen in effects on ODC in peripheral tissues.
The low dose of DEX lowered lung ODC activity during the postweaning spike; heart ODC was elevated during late fetal development but was normal thereafter, and the developmental pattern of enzyme activity in the kidney was generally unaffected by $0.2 \mathrm{mg} / \mathrm{kg}$ of DEX.

\section{DISCUSSION}

Studies in humans have shown that administration of glucocorticoids to stimulate lung surfactant levels in the fetus and newborn may cause long-lasting alterations of development, including neurologic, serologic, and immunologic abnormalities (21-24). In animal models of neonatal steroid treatment, high doses of glucocorticoids have been reported to slow general growth and impair cellular development in the CNS, thus com-

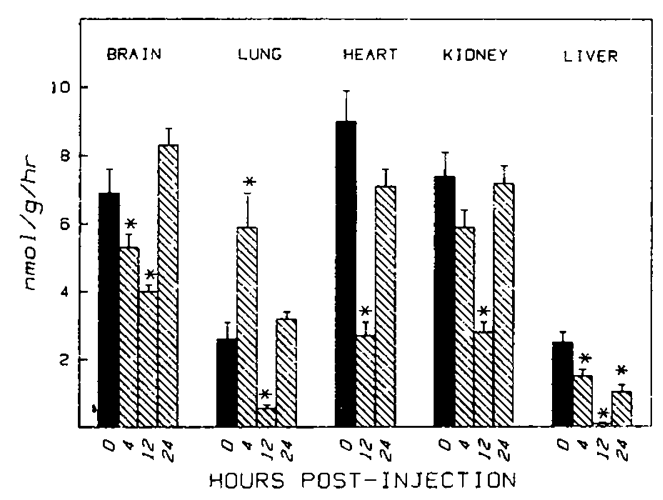

Fig. 3. Acute effects of administration of $2 \mathrm{mg} / \mathrm{kg}$ of DEX on ODC activity in fetal tissues assessed on gestational day 19. Data represent means and SE from fetuses obtained from seven to eight dams at each time point. Asterisks denote individual values that are significantly different from control, as assessed with Duncan's multiple range test.
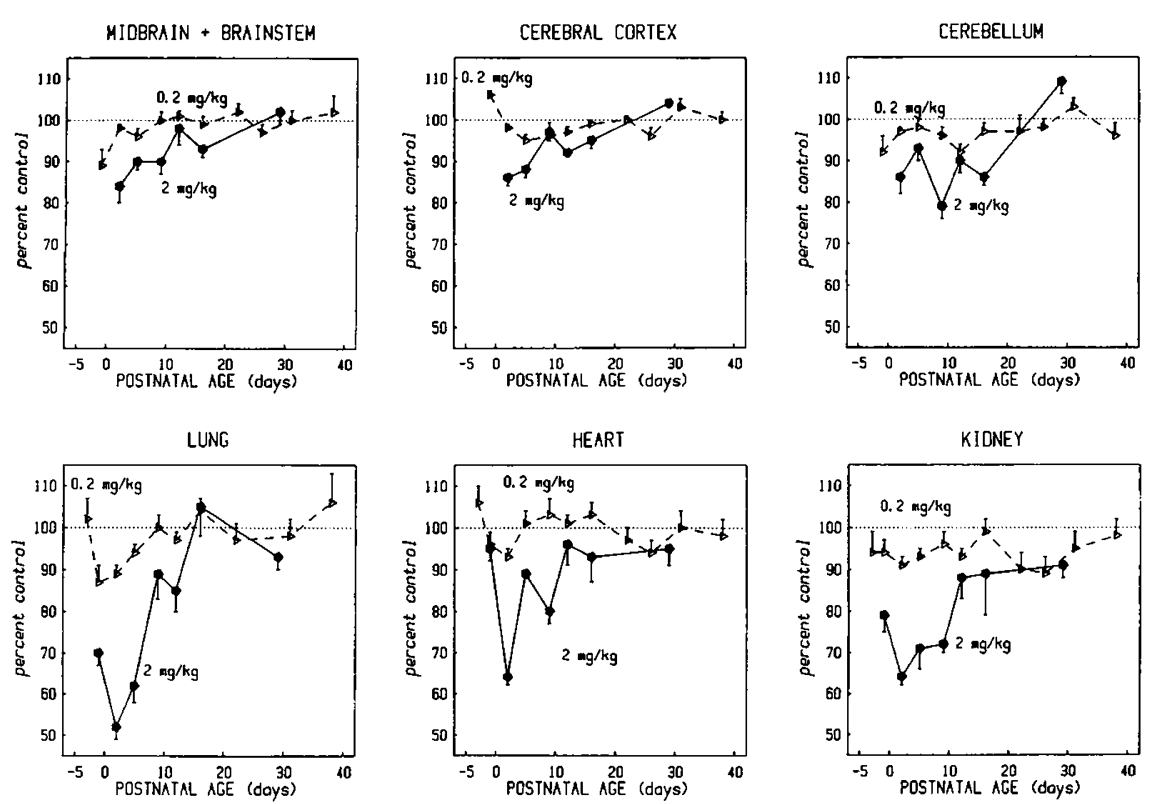

Fig. 2. Effects of maternal DEX treatment on tissue weights in the offspring. Data represent means and standard errors of values from 6-35 animals in each group at each age (number of dams for prenatal points, individual pups for postnatal points). In the three brain regions, global ANOVA indicates a significant lowering of tissue weight caused by DEX, with significant interactions of treatment with age, region, and dose. Significant main treatment effects and interactions of treatment $x$ age were seen individually in each brain region at either dose, with the exception of cerebellum, where the low dose produced a main treatment effect only. Similarly, significant differences were found for DEX effects on peripheral tissues (global ANOVA, main treatment effect with interactions with age, tissue, and dose). The $2 \mathrm{mg} / \mathrm{kg}$ group exhibited significant main treatment effects and interactions of treatment $\times$ age for all tissues; the $0.2 \mathrm{mg} / \mathrm{kg}$ group exhibited main treatment effects for all tissues and a treatment $\times$ age interaction in the lung. 

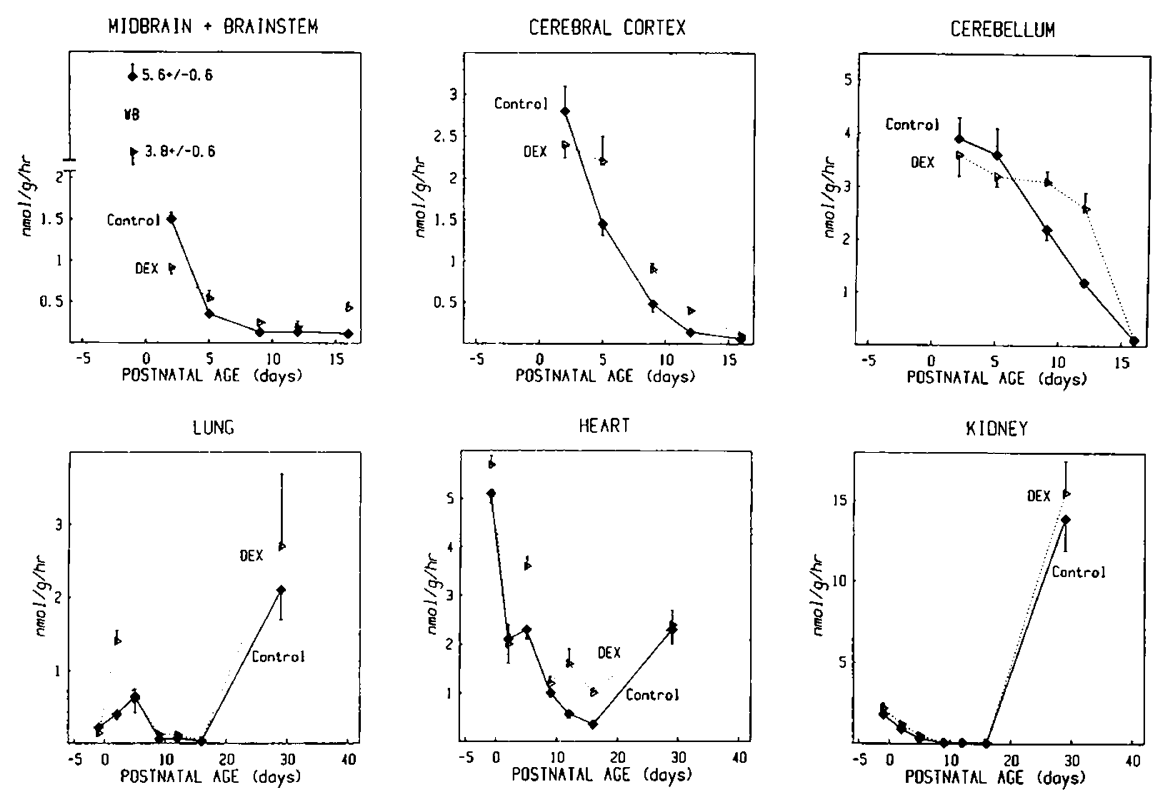

Fig. 4. Effects of maternal administration of $2 \mathrm{mg} / \mathrm{kg}$ of DEX on tissue ODC activity during late gestation and postnatal development. Data represent means and SE of values from six to eight animals in each group at each age (number of dams for prenatal points, individual pups for postnatal points). In the three brain regions, global ANOVA indicates significant alterations of activity caused by DEX (main treatment effect and interactions of treatment with age and region). Main treatment effects and interactions of treatment $\times$ age are significant for each individual region. In the peripheral tissues, global ANOVA also indicates a significant overall elevation (main treatment effect and interactions of treatment with tissue and age); the elevations were significant for each individual tissue, and the interaction of treatment $\times$ age was significant for lung and heart.

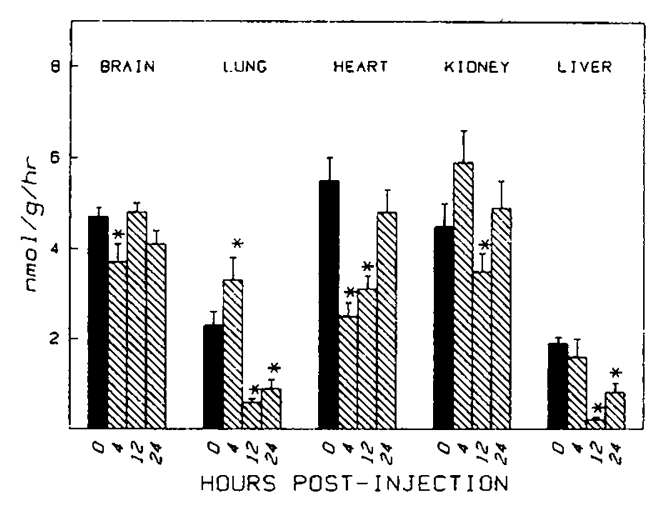

Fig. 5. Acute effects of administration of $0.2 \mathrm{mg} / \mathrm{kg}$ of DEX on ODC activity in fetal tissues assessed on gestational day 19. Data represent means and SE from fetuses obtained from seven to eight dams at each time point. Asterisks denote individual values that are significantly different from control, as assessed with Duncan's multiple range test.

promising acquisition of mature behavioral patterns $(6,7)$. In our study, these findings have been extended to fetal exposure during late gestation: offspring of rats given high doses of DEX ( $2 \mathrm{mg} / \mathrm{kg}$ on gestational days 17,18 , and 19) showed decreased viability and impaired growth. Although body and tissue weights generally reached control levels by weaning, examination of ODC activity in brain regions and peripheral tissues suggested that disruption of cellular maturation had occurred. The typical pattern of acute suppression of ODC followed by prolonged postnatal elevations is associated with delays in replication and differentiation $(6,7,9,10,12)$; this type of alteration has been identified with a variety of insults to the maternal-fetal unit, including environmental intoxicants, endocrinologic abnormalities and exposure to drugs of abuse or selective neurotoxins. It is noteworthy that the lung represents an exception in that it alone showed acute stimulation of ODC activity in the fetal stage. This selectivity can be further exemplified by contrast with liver ODC, which is stimulated by DEX in adulthood (25), but which in the fetus showed suppression. Notwithstanding the acute increase in lung ODC, enzyme activity in this tissue also eventually displayed a "delayed maturation" pattern in the high dose DEX group, suggesting that it too is vulnerable to disrupted cellular development as a consequence of steroid treatment.

The question remains if lowering the dose of DEX can provide a safety factor in the management of respiratory distress. Our results with $0.2 \mathrm{mg} / \mathrm{kg}$, a treatment at the threshold for stimulation of lung surfactant (3), indicated significant and selective acute stimulation of lung ODC without alterations of viability and with only a small degree of growth suppression. Nevertheless, measurement of ODC, particularly in the CNS, still indicated disrupted cellular development, characterized by both short- and long-term suppression of enzyme activity lasting into postnatal life. Although the pattern was not identical to that obtained at higher doses of DEX or with exposure to toxic chemicals (suppression followed by rebound elevations), prolonged reductions in ODC activity have been shown to disrupt neural cell replication, differentiation, migration, and synaptogenesis $(9,14$, 26). It is noteworthy that no brain regional preference was seen even with the low dose of DEX, notwithstanding the fact that the three areas examined have completely different timetables for cellular maturation $(13,14)$.

These results thus suggest that, at least for neural tissues, there is no safe period in which development is spared the adverse effects of glucocorticoids. Although the time course of development is truncated in rodents as compared to man, because vulnerability of the immature brain to steroids extends across a broad range of maturational stages, it is therefore likely that even low doses of glucocorticoids may compromise human development. Our findings with ODC indicate that stimulation of lung maturation by $0.2 \mathrm{mg} / \mathrm{kg}$ of DEX is near the threshold of drug effect; nevertheless, it would be worthwhile to determine if selective actions on surfactant levels can be obtained at even lower doses. 

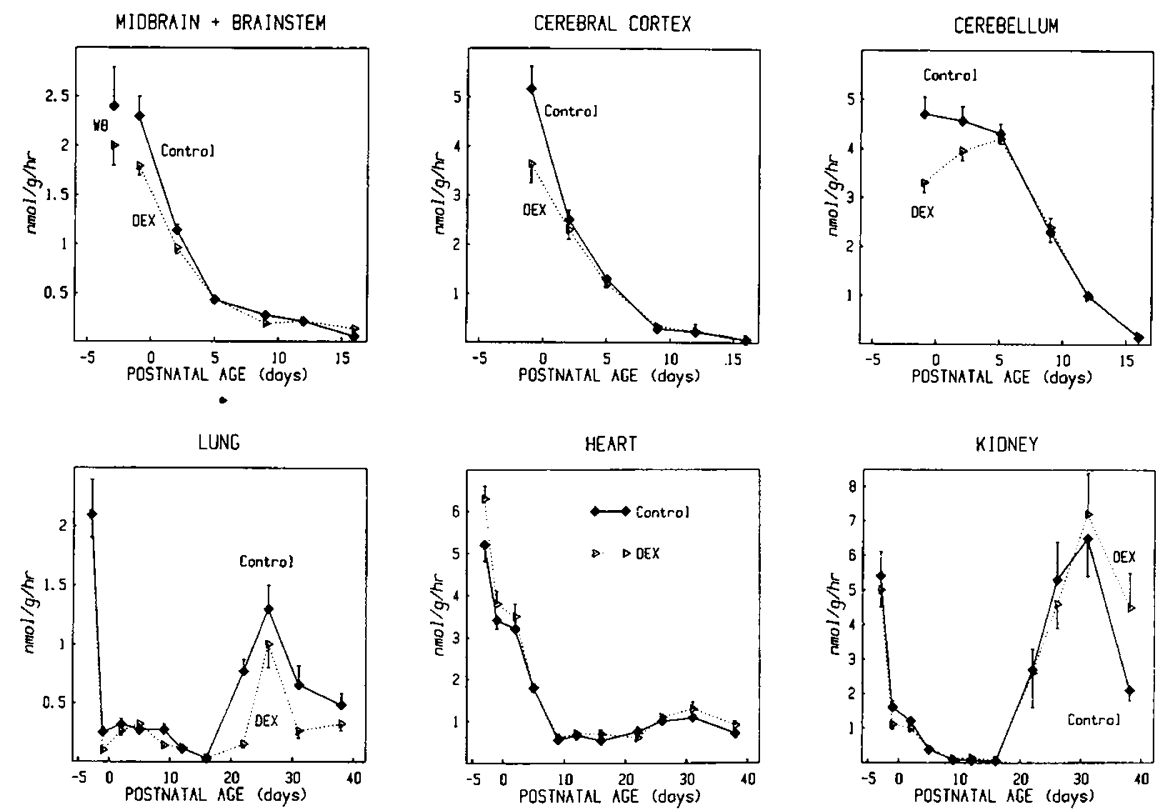

Fig. 6. Effects of maternal administration of $0.2 \mathrm{mg} / \mathrm{kg}$ of DEX on tissue ODC activity during late gestation and postnatal development. Data represent means and standard errors of values from 6-35 animals in each group at each age (number of dams for prenatal points, individual pups for postnatal points). WB values in fetuses on the 19th day of gestation are shown (upper left). In the three brain regions, global ANOVA indicates significant reductions of activity caused by DEX (main treatment effect and interactions of treatment with age and region). Main treatment effects and interactions of treatment $x$ age are significant for each individual region. In the peripheral tissues, significant reductions of activity were seen in lung (main treatment effect and interaction of treatment $\times$ age) and early elevations were seen in the heart (main treatment effect and interaction of treatment $\times$ age)

\section{REFERENCES}

1. Avery ME 1975 Pharmacological approaches to fetal lung maturation. Br Med Bull 31:13-16

2. Papageorgiou A, Stern L 1986 Prevention of the neonatal respiratory distress syndrome: benefits and potential risks for the mother and the infant. Perinatal Med 14:75-86

3. Anderson GG, Lamden M, Cidlowski JA, Ashikaga T 1981 Comparative pulmonary surfactant-inducing effect of three corticosteroids in the nearterm rat. Am J Obstet Gynecol 139:562-564

4. Bohn MC 1984 Glucocorticoid induced teratologies of the nervous system. In Yanai J (ed) Neurobehavioral Teratology. Elsevier, Amsterdam, pp 365-387

5. Howard E 1968 Reductions in size and total DNA of cerebrum and cerebellum in adult mice after corticosterone treatment in infancy. Exp Neurol 22:191208

6. Anderson TR, Schanberg SM 1975 Effect of thyroxine and cortisol on brain ornithine decarboxylase and swimming behavior in developing rat. Biochem Pharmacol 24:495-501

7. Slotkin TA, Barnes G, Lau C, Seidler FJ, Trepanier P, Weigel SJ, Whitmore WL 1982 Development of polyamine and biogenic amine systems in brains and hearts of neonatal rats given dexamethasone: role of biochemical alterations in cellular maturation for producing deficits in ontogeny of neurotransmitter levels, uptake, storage and turnover. I Pharmacol Exp The 221:686-693

8. Heby O 1981 Role of polyamines in the control of cell proliferation and differentiation. Differentiation 19:1-20

9. Slotkin TA, Bartolome J 1986 Role of ornithine decarboxylase and the polyamines in nervous system development: a review. Brain Res Bull 17:307320

10. Slotkin TA, Bartolome J 1987 Biochemical mechanisms of developmental neurotoxicity of methylmercury. Neurotoxicology 9:65-84

11. Slotkin TA, Thadani PV 1980 Neurochemical teratology of drugs of abuse. In: Persaud TVN (ed) Advances in the Study of Birth Defects, Vol 4; Neural and Behavioral Teratology. MTP Press, Lancaster, PA, pp 199-234

12. Slotkin TA, Johnson A, Whitmore WL, Slepetis RJ 1984 Ornithine decarboxylase and polyamines in developing rat brain and heart: effects of perinata hypothyroidism. Int J Devl Neurosci 2:155-161

13. Reinis S, Goldman JM 1980 The Development of the Brain: Biological and Functional Perspectives. Charles C Thomas, Springfield, IL

14. Bell JM, Whitmore WL, Slotkin TA 1986 Effects of $\alpha$-difluoromethylornithine, a specific irreversible inhibitor of ornithine decarboxylase, on nucleic acids and protein in developing rat brain: critical perinatal periods for regional selectivity. Neuroscience 17:399-407

15. Lau C, Slotkin TA 1979 Regulation of rat heart ornithine decarboxylase: Changes in affinity for ornithine evoked by neuronal, hormonal and ontogenetic stimuli. Mol Pharmacol 16:504-512

16. Bell JM, Whitmore WL, Cowdery T, Slotkin TA 1986 Perinatal dietary supplementation with a soy lecithin preparation: effects on development of central catecholaminergic neurotransmitter systems. Brain Res Bull 17:189195

17. Slotkin TA, Orband L, Cowdery T, Kavlock RJ, Bartolome J 1987 Prenatal exposure to methylmercury alters development of adrenergic receptor binding sites in peripheral sympathetic target tissues. Toxicol Lett 35:285-295

18. Slotkin TA, Orband-Miller L, Queen KL, Whitmore WL, Seidler FJ 1987 Effects of prenatal nicotine exposure on biochemical development of rat brain regions: maternal drug infusions via osmotic minipumps. J Pharmacol Exp Ther 240:602-611

19. Grignolo A, Kuhn CM, Schanberg SM 1982 Maturation of growth hormone stimulation of kidney ornithine decarboxylase in the rat. Life Sci 30:383390

20. Slotkin TA, Lau C, Kavlock RJ, Whitmore WL, Queen KL, Orband-Miller L Bartolome M, Baker FE, Cameron AM, Antolick L, Bartolome JV 1988 Trophic control of lung development by sympathetic neurons: effects of neonatal sympathectomy with 6-hydroxydopamine. J Dev Physiol (in press)

21. Fitzhardinge PM, Eisen A, Lejteny C, Metrakos K, Ramsay M 1974 Sequelae of early steroid administration to the newborn infant. Pediatrics 53:877-883

22. Otero L, Conlon C, Reynolds P, Duval-Amould B, Golden SM 1981 Neonatal leukocytosis associated with prenatal administration of dexamethasone. Pediatrics 68:778-780

23. MacArthur BA, Howie RN, Dezoete JA, Elkins J 1981 Cognitive and psychosocial development of 4-year-old children whose mothers were treated antenatally with betamethasone. Pediatrics 68:638-643

24. Gunn T, Reece ER, Metrakos K, Colle E 1981 Depressed T cells following neonatal steroid treatment. Pediatrics 67:61-67

25. Slotkin TA, Bartolome J 1983 Ornithine decarboxylase: marker of neuroendocrine and neurotransmitter actions. Methods Enzymol 103:590-603

26. Slotkin TA, Seidler FJ, Whitmore WL, Weigel SJ, Slepetis RJ, Lerea L, Trepanier PA, Bartolome J 1983 Critical periods for the role of ornithine decarboxylase and the polyamines in growth and development of the rat: Effects of exposure to $\alpha$-difluoromethylornithine during discrete prenatal or postnatal intervals. Int J Dev Neurosci 1:113-127 